\title{
PLANEJAMENTO ESCOLAR : NOVOS PARADIGMAS, POLÍTICAS E EXPERIÊNCIAS NUM CONTEXTO DE GLOBALIZAÇÃO
}

\section{Nilson Joseph Demange}

\section{RESUMO}

Este artigo trata da influência dos altos padrões de formação básica e tecnológica dos trabalhadores dos países mais desenvolvidos sobre a produtividade e desempenho empresarial desses países tem
permitido
a eles
estabelecerem,
no
sistema
de
mercado.

\section{PALAVRAS-CHAVE}

Escolas - Planejamento; Globalização

\section{ABSTRACT}

This article deals with the influence of the high standards of basic formation and technological of the workers of the countries more developed on the productivity and enterprise performance of these countries it has allowed they to establish, in the market system.

\section{KEYWORDS}

School - Planning; Globalisation 


\section{INTRODUÇÃO}

A influência dos altos padrões de formação básica e tecnológica dos trabalhadores dos países mais desenvolvidos sobre a produtividade e desempenho empresarial desses países tem permitido a eles estabelecerem, no sistema de mercado internacional ou através de mercados regionais, condições de competitividade muito favoráveis para seus produtos e serviços. O reconhecimento desse fato tem sido aceito no contexto de globalização da economia atual, como uma condição necessária para os países em desenvolvimento, agregados também em blocos econômicos como o Brasil no Mercosul, modernizarem sua economia. Por outro lado, a educação básica tem sido progressivamente incorporada, também, através de novos paradigmas nacionais e internacionais de planejamento das diversas políticas públicas ou sociais, à tendência de integração democrática da população, no conhecimento e deliberação sobre os temas ou problemas de seu interesse e direitos na sociedade atual.

A formação histórica dessas tendências educacionais enfrentou, o desafio da diversidade e especificidade das condições locais, regionais, políticas, econômicas, sociais, éticas, estéticas e culturais existentes no país, que também exercem influência sobre a formação educacional básica da população. No regime militar brasileiro uma tentativa de enfrentar essas condições foi, em 1971, ampliar o período de tempo da educação escolar obrigatória -anteriormente de quatro anos segundo a Lei de Diretrizes e Bases da Educação, LDB - de 1961. Foram acrescentados os quatro anos seguintes - Lei 5692, 1971. Essa orientação foi reassumida através da Constituição de 1988, com apoio da sociedade civil e através da nova LDB de 1996 - Art. 4 e 32. Além da ampliação da escolaridade obrigatória dos oito anos de ensino fundamental e da progressiva obrigatoriedade nela assinalada para o ensino médio, a atual LDB destaca também as diretrizes quanto a qualidade, a diversidade, a flexibilidade e descentralização dos processos e sistemas educacionais.

As políticas públicas elaboradas pelo Congresso e pelo Governo para implementar e viabilizar um processo de planejamento educacional, segundo essas diretrizes e metas, geraram também diversos mecanismos e experiências, de acordo com a diversidade e especificidade das condições locais ou regionais do país. No entanto, uma característica marcante tem sido a forte influência do poder central nas transformações pelas quais passa a educação básica,

considerada

neste

estudo. 


\section{CONTROLE CENTRAL DAS POLÍTICAS E ESTRATÉGIAS EDUCACIONAIS}

As formas centralizadas de organização, gestão e avaliação das políticas públicas, possibilitadas pela nova LDB, permitiram ao Governo da União " a coordenação da política nacional da educação articulando os diferentes níveis e sistemas e exercendo função normativa, redistributiva e supletiva em relação às demais instâncias educacionais"- LDB, Art.8, par.1. Caberia assim às demais instâncias do país adequarem-se ao papel central do Governo da União na organização do seu próprio sistema de ensino, como também em relação aos dos Estados, Distrito Federal e Municípios: "Os sistema de ensino terão liberdade de organização nos termos desta Lei" [grifo nosso] - LDB, Art.8, par.2.

Dessa forma, o Conselho Nacional de Educação ao ser criado por lei deveria ser integrado como parte dessa estrutura educacional centralizada, dentro da qual exerceria suas "funções normativas, de supervisão e atividade permanente"- LDB, Art.9, item IX, par.1. Definiu-se assim, uma estrutura hierárquica das competências governamentais na qual os espaços, para a participação civil autônoma nas políticas educacionais, deveriam limitar-se a funções apenas complementares e de assessoramento às decisões governamentais. Essa estrutura deveria ser ainda flexível e, para isso, caberia ainda à União a elaboração também do Plano Nacional de Educação "em colaboração com os Estados, Distrito Federal e os Municípios" - LDB, Art.9, item I - e com seus respectivos sistemas de ensino, "definirem as normas de gestão democrática do ensino público na educação básica, de acordo com suas peculiaridades e os seguintes princípios: I -participação dos profissionais da educação na elaboração do projeto pedagógico da escola, II - participação das comunidades escolar e local em conselhos escolares ou equivalentes" - Art.14, itens I e II.

\section{PLANEJAMENTO, PADRÕES MÍNIMOS E FLEXIBILIDADE CURRICULAR}

A iniciativa política governamental através do Ministério da Educação e Cultura MEC que resultou, além da aprovação de seu projeto substitutivo da LDB na aprovação também da emenda constitucional \#14, promoveu na mesma ocasião mudanças favoráveis à centralização de seu controle sobre o Fundo de Manutenção e Desenvolvimento do Ensino 
Fundamental e de Valorização do Magistério instituído por ela. Dessa forma, ficaram também assegurados os recursos financeiros, principalmente provenientes dos Estados, dos Municípios e Distrito Federal, que junto aos da União garantiriam um "padrão mínimo de oportunidades educacionais para o ensino fundamental, baseado no custo mínimo por aluno, capaz de assegurar ensino de qualidade". Assim ficaram igualmente respaldadas as iniciativas anteriores do MEC, visando a adequação do Ensino Fundamental aos parâmetros curriculares nacionais, os quais foram divulgados já em agosto de 1996, em consonância com a LDB apenas aprovada no final daquele ano.

Estes parâmetros foram propostos pelo MEC, de acordo com a apresentação dos mesmos existente no PCN de Ciências Naturais: com a finalidade de "subsidiar os educadores brasileiros no debate para re-elaboração dos currículos de Ciências Naturais nos Estados e Municípios, tendo em perspectiva as relações entre Ciência, Tecnologia e Sociedade, fundamental para a compreensão do mundo em que vivemos". Propõem, para isso, um ensino ativo "em que os conteúdos deixam de ser listagens de tópicos, pedaços alinhavados das disciplinas científicas", para articularem-se "em conjunto de conteúdos que podem ser estudados em uma diversidade de temas, possibilitando escolhas que levem em conta a realidade local". - PCN, Ciências Naturais, 1996.

Assim os conteúdos foram agrupados nos seguintes blocos temáticos: Ambiente Natural e Construído, Ser Humano e Saúde, Recursos Técnicos e Tecnológicos, Terra e Universo. Os três primeiros deveriam desenvolver-se ao longo de todo o ensino fundamental e o último depois deles.

Essa proposta continha, além dos temas específicos, de conteúdos ligados às Ciências Naturais, outros "temas transversais", como o de Convívio Social e Ética, que os articulavam com os temas da área de Ciências Sociais e os desta com temas cotidianos de questões, problemas, valores, atitudes e participação, necessários à cidadania e democracia.

A importância das áreas de conhecimento convencionais ministradas pelas escolas, tais como Língua Portuguesa, Matemática, Ciências, História e Geografia deveria também ser mantida. Além disso, seriam acrescidas de forma articulada aos seus conteúdos específicos aquelas outras questões igualmente importantes tratadas pelos temas transversais a 
serem introduzidos no currículo, tais como por exemplo: o exercício da cidadania, a violência, a saúde, o uso dos recursos naturais, os preconceitos, bem como temas locais. - Convívio Social e Ética, Temas Transversais , 1996.

Muitos desse novos temas para a educação correspondem a princípios, metas e objetivos de conteúdos morais, sociais, econômicos, políticos e culturais, já explícita e implicitamente tratados, embora com menor desenvolvimento, pela Constituição de 1988 e depois, de forma mais ampla, também pela LDB.

As mudanças estabelecidas pela já mencionada Emenda Constitucional \#14 de 1996, serviram para reforçar o papel do MEC, também como definidor dessas políticas educacionais curriculares antes iniciadas e das que seriam por ele ainda desenvolvidas.

Outras propostas de políticas, apesar disso, surgiram também na sociedade civil e contribuíram desde muito antes para o resultado dessas oficiais em muitos aspectos, com posições diversas ou semelhantes, provindas de vários movimentos principalmente de organizações de educadores. Alguns desses atuaram antes junto ao Legislativo, como por exemplo, após a IV Conferência Brasileira de Educação que em agosto de 1986 elaborou a "Carta de Goiânia" sobre Educação e Constituinte. - Saviani, 1997 Igualmente surgiu, também, após a Constituição, o Fórum Nacional em Defesa da Escola Pública na LDB. Pino, 1997

A incorporação da diversidade social desse contexto na área da educação tornouse, para o MEC, um desafio a ser incorporado ao princípio democrático - sustentado pela coalizão partidária de apoio ao governo - segundo o qual seria necessário uma definição ampla de critérios para avaliação das políticas curriculares , que iria além das questões técnico administrativas ou instrumentais do ensino e da aprendizagem nas diversas áreas do conhecimento.

Isso manifesta-se, por exemplo, no PCN sobre Convívio Social e Ética: "É preciso atentar para o fato de que a avaliação de valores, normas, atitudes e procedimentos, que tem presença marcante entre os conteúdos de Convívio Social e Ética é bastante difícil. Fazê-la exige que a comunidade escolar tenha claro os valores, as normas e atitudes que afirma , os procedimentos que pretende que o aluno aprenda e que o professor explicite-os e crie situações de aprendizagem em função deles. Ao colocar a possibilidade da avaliação não se pode deixar de salientar os limites da atuação da escola nessa formação" [...] "não se trata de 
impor determinados valores, mas de ser coerente com os valores assumidos e de permitir aos alunos uma discussão sobre eles." - Convívio Social e Ética pp. 33/34. Assim fica claro nessa proposta a importância da variedade de critérios da avaliação ser ampla, para permitir um planejamento escolar coletivo e participativo. Nesse contexto, "a finalidade principal das avaliações desses conteúdos - Convívio Social e Ética - é ajudar os educadores a planejar a continuidade de seu trabalho, ajustando ao processo de seus alunos, buscando oferecer a eles condições de superar obstáculos e desenvolver o autoconhecimento e a autonomia - e nunca qualificar os alunos" [...] "Disso decorre a necessidade de se lançar mão de diferentes instrumentos e nunca avaliar isoladamente" [...] "compondo assim, uma avaliação processual mais complexa. Auto avaliações e avaliações em grupo, assim como o retorno e a discussão com os alunos da avaliação feita pelo professor [...]" - PCN: Convívio Social e Ética pg.34.

Segundo o texto, a possibilidade da clareza dessa visão ampla de avaliação, a partir da sala de aula, seria considerada mais complexa quando realizada a nível da escola e, ainda mais, quando considerada a nível das políticas educacionais dos municípios, dos estados ou país como um todo. Isso parece indicar a possibilidade de reconhecimento também da existência das várias tendências políticas educacionais e de seus representantes individuais ou hegemônicos, tanto no âmbito do MEC como no de órgão específicos a ele articulados. Isso parece evidenciar-se , por exemplo, em dois importantes pareceres do Conselho Nacional de Educação, como veremos a seguir.

\section{NOVOS PARADIGMAS DA AVALIAÇÃO CURRICULAR: DOS PARÂMETROS ÀS DIRETRIZES}

Os currículos e seus conteúdos mínimos, propostos pelo MEC - artigo 9 letra E da lei 9131/95 - deveriam ser apresentados à Câmara de Educação Básica do Conselho Nacional de Educação CNE, como propostas de regulamentação da base curricular nacional e de organização do ensino básico a serem transformadas em diretrizes.

A Câmara de Educação Básica, durante o ano de 1996, elaborou uma proposta preliminar dessas diretrizes para o Ensino Fundamental, na qual identifica-se a tendência de uma avaliação educacional diversificada, com ênfase na formação de identidades e baseada na interação entre processos de conhecimento e afetivos dentro de uma base comum nacional. 
A Proposta Preliminar daquelas diretrizes foi assim assumida por sua relatora:

- $\quad$ "1- As Escolas Brasileiras deverão estabelecer os Princípios Éticos da Autonomia e Solidariedade como norteadores de suas de suas ações pedagógicas.

- 2- As Escolas Brasileiras deverão reconhecer a Identidade Pessoal de Alunos e $\underline{\text { Professores e a Identidade de Cada Unidade Escolar e de seus Respectivos Sistemas }}$ Estaduais e Municipais [grifos nossos].

- 3- As Escolas Brasileiras devem reconhecer que as identidades são constituídas na interação entre os processos de Conhecimento e os Afetivos, como conseqüência de ações inter e intra-subjetivas entre os vários participantes do contexto escolarizado. As diversas experiências de vida de alunos, professores e demais participantes do ambiente escolar, expressas através de múltiplas formas de diálogo contribuem para a constituição de conhecimentos e valores indispensáveis à vida cidadã.

- 4- Em todas Escolas Brasileiras deverá ser garantida a igualdade de acesso para Alunos e Professores a uma Base Comum Nacional, de maneira a legitimar a unidade e a qualidade da ação pedagógica, na diversidade nacional. Esta Base Comum Nacional deverá fundamentar-se em Princípios Éticos, Estéticos e Políticos que traduzam as relações entre a Educação Fundamental e o Meio Ambiente , o Trabalho, a Ciência, a Tecnologia, a Sociedade , a Cultura e as Linguagens.

- 5- Através das Propostas Curriculares, as Escolas Brasileiras deverão explicitar processos de ensino voltados para as relações com sua comunidade local, regional, nacional e planetária, em que os direitos e deveres da cidadania expressem as relações entre os Princípios Éticos, Estéticos e Políticos da Educação com o Meio Ambiente, o Trabalho, a Ciência, a Tecnologia, a Sociedade e a Cultura e as Linguagens.

- 6- As Escolas Brasileiras organizarão as Áreas de Conhecimento alimentadas pelos conteúdos da Disciplina de Língua Portuguesa, Língua Materna, Matemática, Geografia, História, Ciências, Educação Artística, Educação Física, Educação Religiosa e Línguas Estrangeiras, em torno das ligações entre os Princípios Éticos, Estéticos e Políticos da Educação com o Meio Ambiente, o Trabalho, a Ciência, a Tecnologia, a Sociedade e a Cultura e as Linguagens. 
- 7- As Escolas Brasileiras utilizarão a Parte Diversificada de suas Propostas Curriculares, para enriquecer a Base Comum Nacional e propiciar de maneira específica a introdução de projetos e atividades pedagógicos em interesse de suas comunidades locais." - Diretrizes Curriculares Nacionais, Parecer Preliminar da Relatora Regina de Assis, s.d. -

O MEC enviou em julho de 1997 também à Câmara de Ensino Básico do CNE suas propostas da base curricular e organização do ensino médio. O trabalho sobre as diretrizes para o ensino fundamental, já realizado nessa Câmara, permitiu incorporar e desenvolver na elaboração das diretrizes para o ensino médio, as principais ênfases daquelas diretrizes anteriores. Isso é destacado já na Introdução do novo parecer ao referir-se aos "Princípios Estéticos, Políticos e Éticos que inspiraram a LDB e , por conseqüência devem inspirar o currículo. A decisão da CEB em deter-se mais longamente nesse terceiro aspecto, deve-se em grande medida ao consenso construído durante a discussão das DCNs em torno desse princípios, que por serem seu produto nelas aparecem menos desenvolvidos". - DCNs para o Ensino Médio, Parecer aprovado em 01/06/1998 - Relatora: Guiomar Namo de Mello.

Várias entidades educacionais civis são listadas também na Introdução desse Parecer, além dos órgão governamentais, como participantes solidários, que legitimam ao ver da Relatora o trabalho de elaboração das diretrizes desenvolvido a partir da proposta original do MEC. Entre eles estão a Associação Nacional de Pós Graduação em Educação - AMPEd, a Confederação Nacional de Trabalhadores da Educação - CNTE, o CONSED, o Fórum dos Conselhos Estaduais de Educação, a União Nacional de Dirigentes Municipais de Educação, as universidades públicas e privadas, as associações de escolas particulares de ensino médio, as instituições do sistema S - SENAI, SENAC, SENAR -, as SEMTEC, as escolas técnicas federais.

Além do destaque quanto os princípios estéticos, políticos e éticos , o parecer acima desenvolve dois aspectos distintos dos antes considerados nos PCNs e nas diretrizes para o Ensino Fundamental. O Trabalho é apresentado juntamente com a Cidadania, como o contexto mais importante da experiência curricular no ensino médio, tendo como base diretrizes já traçadas pela LDB, em seus artigos 35 e 36. A importância desse Contexto do conhecimento é assim apresentada: "O tratamento contextualizado do conhecimento é o recurso que a escola tem para retirar o aluno da condição de expectador passivo. Se bem 
trabalhado permite que, ao longo da transposição didática, o conteúdo do ensino provoque aprendizagens significativas que mobilizem o aluno e estabeleçam entre ele e o objeto de conhecimento uma relação de reciprocidade. A contextualização evoca por isso área, âmbitos ou dimensões presentes na vida pessoal, social e cultural e mobiliza competências já adquiridas. As dimensões da vida ou contextos explicitamente valorizados pela LDB são o trabalho e a cidadania. "- op. cit., p.44. Esta última é vista também como parte do trabalho escolar. Através desse processo, segundo o parecer, seria possível conduzir o aluno a adquirir a competência de uma análise crítica da realidade social em que vive: "na medida em que a contextualização facilita o significado da experiência de aprendizado escolar [mais abstrata] e a re-significação da aprendizagem baseada na experiência espontânea [mais concreta], ela pode - e deve - questionar os dados desta última: os problemas ambientais , os preconceitos e esteriótipos, os conteúdos da mídia, a violência nas relações pessoais, os conceitos de verdadeiro e falso na política e assim por diante." [grifos nossos] -op. cit., p.50. Desenvolvendo, depois, mais especificamente o contexto do trabalho este é assim apresentado:

\begin{abstract}
"A dimensão do trabalho na medida em que ele é princípio organizador do currículo, muda inteiramente a noção de educação geral acadêmica ou melhor dito , academicista . O trabalho já não é mais limitado ao ensino profissionalizante. Muito ao contrário , a lei reconhece que nas sociedades contemporâneas, todos, independentemente de sua origem ou destino sócio-profissional, devem ser educados na perspectiva do trabalho, enquanto uma das principais atividades humanas, enquanto campo de preparação para escolhas das principais atividades humanas , enquanto campo de preparação para escolhas profissionais futuras, enquanto processo de produção de bens e conhecimentos com as tarefas laborais que lhes são próprios"[...] "conhecimentos e competências constituídos de forma assim contextualizada constituem educação básica, são necessários para a continuidade de estudos acadêmicos e aproveitáveis em programas de preparação profissional seqüenciais ou concomitantes com o ensino médio, sejam eles cursos formais seja a capacitação em serviço. Na verdade constituem o que a LDB refere como a preparação básica para o trabalho". Op. cit., p.45.
\end{abstract}

A implementação dessas diretrizes como políticas educacionais do Governo Federal e dos Estados foi programada através do PROMED - Programa de Melhoria e Expansão do Ensino Médio. [...] "Com ele o ministério da Educação por meio da SEMTEC Secretaria de Educação Média e Tecnológica - aportará recursos financeiros e técnicos para que os Estados e o Distrito Federal respondam com equidade à crescente demanda por esse nível de ensino" [...] "O financiamento das ações será negociado com as unidades federadas em função a sua capacidade para equacioná-las através de projetos e aportar contrapartida." Esta parte dos Estados e Distrito Federal seria de 45\% do custo total de US\$1.0 bilhão, sendo 
5\% a parte de União e o restante financiado pelo BID. - PROMED,1999, pg. 43/44. Esse sistema de financiamento internacional já era mantido também com o BIRD - Banco Mundial , mesmo diretamente, com alguns Estados.

É o caso do Estado de Minas Gerais, onde foram amplas as repercussões dessas mudanças de paradigmas ocorridas em nivel federal. Em relação a ele também será importante reconhecer algumas afinidades entre essas reformas políticas educacionais realizadas no Brasil e as principais "Priorities and Estrategies for Education", do relatório com o mesmo nome do BIRD - Banco Mundial. O que pode ser observado, principalmente, no seguinte destaque feito por esse banco quanto ao financiamento da Educação: "The World Bank continue to support financial and managerial change of education sistems on a countryby-country basis through an increasing focus on sectorwide policy and through the increasing lending of funds for public investments in primary and lower secondary education". - The Worl Bank, January 24,1965 - Executive Sumary, 50.

\section{REPERCUSSÕES DAS MUDANÇAS NOS PARADIGMAS E POLÍTICAS EDUCACIONAIS DO ESTADO DE MINAS GERAIS}

A Secretaria Estadual de Educação de Minas Gerais criou também alguns projetos , segundo essas diretrizes, como o PROCAD-Projeto de Capacitação de Dirigentes das Escolas Públicas -PROCAD, 4/SEE, MG/1998, que integra o anterior PROQUALIDADEProjeto de Melhoria da Qualidade do Ensino Fundamental - SEE,MG/1993 - com o apoio do Banco Mundial, em 1995.

Essas políticas partem do pressuposto de um processo educativo, o qual segundo a LDB "abrange os processos formativos que se desenvolvem na vida familiar, na convivência humana, no trabalho, nas instituições de ensino e pesquisa, nos movimentos sociais e organizações da sociedade civil e nas manifestações culturais"- LDB,Art.1.

Daí porque, segundo esse programa a educação escolar , primeiramente, "não pode restringir-se à mera transmissão de conhecimentos, mas deve contribuir para formar um sujeito capaz de elaborar um ponto de vista sobre os fatos e fenômenos da vida [competência cognitiva]; em segundo lugar capaz de comunicar seu ponto de vista a outros, ouvir de outros e modificar seu próprio ponto de vista se assim julgar necessário [competência comunicativa]; 
e além disso, capaz de assumir consciente e criticamente as funções técnicas e políticas requeridas pela sociedade [competência social] " - PROCAD,pag.26. [destaques do contexto]

Em aparente coerência com essas diretrizes foi decidida a implantantação do sistema de ciclos no ensino fundamental.

Do ponto de vista pedagógico, a organização desse sistema pressupunha que: " a) a educação é um processo formativo e não informativo; b) a aprendizagem do saber organizado é parte do processo formativo e não o fim da educação; c) o tempo escolar é o de formação do aluno e não o tempo fragmentado em séries; d) os alunos devem ser considerados em suas diferenças, do mesmo modo que os professores e os estilos de ensinar; e) os professores e os alunos necessitam de maior grau de liberdade de ação; f) a vontade do aluno deve ser trabalhada mais do que o sentido da obrigação visando desenvolver-lhe o sentido ético da vontade; g) a cooperação deve ser buscada, em detrimento da competitividade, já que ninguém será avaliado em comparação com os outros, mas em função dos próprios progressos.

Do ponto de vista metodológico, segundo essas diretrizes [de influência clara construtivista] será possível : " a) desenvolver um processo educativo construtivo e estruturante e não simplesmente receptivo, estruturado e repetitivo; b) Articular vários tipos de saberes e experiências e não apenas as habilidades resultantes de um saber específico; c) maior grau de diversificação metodológica e curricular."

Essa proposta contempla ainda, em relação à organização:

\footnotetext{
" 1) a implantação do Regime de Progressão Continuada; com a organização desse regime em 2 ciclos, o primeiro compreendendo os 4 primeiros anos do ensino fundamental e, o segundo os 4 últimos; 2) condicionamento da conclusão de ciclo primeiro ou segundo- ao resultado da avaliação realizada pelo Conselho de Classe, com base em avaliações realizadas pelos professores ao longo do processo formativo do aluno durante o ano letivo; 3) criação de estudos complementares que deverão ser realizados, entre o final do último ano letivo de cada ciclo e o início do seguinte, pelos alunos de desempenho considerado insatisfatório em cada ciclo; 4) oferta de currículos diferenciados pelas escolas, de acordo com suas possibilidades; 5) avaliação contínua, com apresentação periódica dos resultados durante o ano letivo, pelo que o Conselho de Classe indicará a alternativa curricular mais adequada aos alunos no ano seguinte." (PROCAD/4, 1998).
} 
Percebe-se nesse conjunto de procedimentos, entre a Progressão Continuada e a Avaliação Contínua, principalmente, uma dedicação do ensino voltada à estabilidade e equilíbrio do processo de aprendizagem interno da escola.

Os aspectos curriculares, ressaltados pelos PCN e Pareceres anteriores, relacionados com a construção da Identidade, no contexto da Diversidade social em que a escola deve situar-se como Instituição Autônoma na comunidade e no mundo atual, parecem estar descolados em relação a essa proposta, voltada para uma organização avaliativa centrada nos processos internos da escola.

Esses objetivos relacionados com a implantação da proposta mais ampla da organização da escola e de seu currículo, aparecem de forma mais clara no Programa de Melhoria do Ensino Médio -PROMEDIO, que foi elaborado após o do Ensino Fundamental. Este já teve por base um empréstimo do Banco Mundial, negociado desde 1991 mas aprovado em 1993, e que foi bem avaliado no acompanhamento feito pelo mesmo banco em 1998. Banco Mundial, "Project Implementation Status", MG Proqualidade/ 3733-BR, June 30, 1998

O projeto de melhoria do ensino médio visava, também, viabilizar a política de dar seqüência aos objetivos de universalização da...

\footnotetext{
" educação básica de qualidade". Os seus objetivos mais amplos foram assim expressos: "Dessa forma, procurou-se enfrentar a nova ordem econômica e social, com base na valorização do ser humano e de sua capacidades de comunicar-se, de aprender e de responder criativamente às mudanças que vêm ocorrendo na sociedade e no processo produtivo. Nesse quadro, a demanda por matrícula no ensino médio tende, hoje, a aumentar significativamente, quer em função das exigências de escolaridade que se impõem no mundo atual, quer em decorrência do próprio desenvolvimento de políticas voltadas para a melhoria do ensino fundamental, cujo sucesso determina a elevação do número de concluintes desse nível em condições de aspirar o prosseguimento de seus

estudos." (PROMEDIO, SEE/MG-1998).
}

Com esse objetivo, em novembro de 1995, foram encaminhados textos para discussão nas escolas, cujos resultados subsidiaram a elaboração de um documento preliminar sobre as Políticas Públicas do Ensino Médio. "Esse documento foi divulgado, analisado e discutido em 141 seminários, por Pólos Regionais, ERE, municípios e escolas, com a participação de 172.000 pessoas de diversos segmentos da sociedade: professores, colegiados, 
pais, alunos, sindicatos, universidades, etc."[...] Como resultado a SEE/MG formulou as seguintes metas que pretende atingir em 10 anos: [...]

" Regularização do fluxo escolar na educação básica, evitando o desperdício de recursos financeiros e criando espaço físico para o atendimento a um número maior de alunos.

Oferta de um ensino médio destinado a propiciar uma sólida formação geral, em dia com as modernas conquistas científicas e tecnológicas, que busque uma compreensão mais aprofundada na abordagem de temas de estudos que supere o enciclopedismo acadêmico que caracteriza o ensino médio brasileiro.

Implantação de centrais de informática e de línguas, a partir das quais o uso de computadores e de línguas estrangeiras modernas se transformem em fatos corriqueiros em nossas escolas.

Desenvolver um programa de formação continuada de professores, possibilitando a eles refletir e questionar sua prática pedagógica, tendo em vista a sua preparação para promover o desenvolvimento de habilidades de pensamento dos alunos e a aquisição de valores mais ajustados a uma sociedade em processo de desenvolvimento, comprometida com as formas democráticas de participação social e cultural.

Criação de centros regionais de educação profissional, para a oferta dessa modalidade de ensino, qualificando as vagas oferecidas para esses cursos, bem como sintonizando sua oferta às necessidades potenciais do mercado de trabalho, em todas as regiões do Estado."[...]

Para a SEE/MG, "tais ações são decisivas no sentido de se conseguir um ensino médio de qualidade, atualizado, moderno e dinâmico, aberto para todos os cidadãos do Estado. Nessa perspectiva, torna-se especialmente relevante a atenção dada ao ensino de uma base comum nacional do currículo, cuja solidez constitui um requisito indispensável par qualquer política de ensino médio".

No sentido de implementar essas ações, essa Secretaria diagnosticou entre as possíveis razões do fracasso de muitas tentativas de renovação curricular em vários estados e 
países , "as resistências oferecidas pelos professores e outros especialistas, pelos dirigentes educacionais ou pela comunidade escolar". Daí, a adoção de um "modelo aberto"de elaboração da nova proposta curricular e dos materiais correspondentes. Neste modelo, "o trabalho dos especialistas especialmente contratados para essa tarefa foi sendo discutido com professores que atuam na sala de aula. Assim foram envolvidos ativamente no processo de reexame e avaliação das propostas curriculares atuais, no que tange às suas diretrizes e aos conteúdos, bem como na produção e na aplicação dos materiais didáticos destinados a sua operacionalização, aumentando significativamente as possibilidades de que os novos currículos saiam do papel e contribuam para a melhoria do ensino."- op.cit, pag.1

Neste aspecto foi dado ênfase às características ou identidade institucional da escola, incentivada em sua autonomia, através dessa estratégia de relações pedagógicas mais democráticas. Isso foi assumido conscientemente como uma "abordagem institucional da inovação curricular pela qual a escola foi tomada como um sistema social, com dinâmica própria, onde qualquer processo de mudança precisa ser trabalhado de forma global. Nessa perspectiva, foi fundamental o esforço de sensibilização dos dirigentes escolares e dos professores das escolas envolvidas, cuja adesão voluntária constitui um critério fundamental para a composição da amostra de escolas e docentes incluídos no Programa-Piloto."

Essa característica foi retomada na análise da nova estrutura curricular do ensino médio a ser implantada a partir de 1999, como sendo apenas "o primeiro passo de um processo em que as escolas irão gradativamente conquistando maior autonomia e maior grau de liberdade para definir seu próprio perfil e a sua identidade."[...] "Portanto, identidade, diversidade e autonomia devem ser os traços da nova escola de ensino médio." - op.cit.,pg. 38

A identidade é vista assim como "um pré-requisito, junto com a diversidade e a autonomia, para garantir um patamar comum nos pontos de chegada", tendo como fundamento parecer da Câmara de Educação Básica do Conselho Nacional de Educação sobre o ensino médio: "Identidade supõe uma inserção no meio social que leva à definição de vocações próprias, que se diversificam ao incorporar as necessidades locais, e as características dos seus alunos e participação de professores e das famílias no desenho institucional considerado adequado para a escola"[...] "a diversidade da escola média é necessária para contemplar as desigualdades nos pontos de partida dos seus alunos, que requerem diferenças de tratamento como forma eficaz comum nos pontos de chegada". 
Essas propostas parecem bem articuladas e com algumas práticas já delineadas no âmbito do sistema escolar. Deixam um grande vazio, entretanto, sobre como a inserção da escola no meio social poderá desenvolver-se, através de outras práticas também válidas para a construção da identidade e da autonomia. Estas precisariam ser dirigidas, então, a relações mais amplas, numa sociedade cujas comunicações instrumentais são cada vez mais dinâmicas e globalizadas mas ao mesmo tempo pouco aprofundadas nos aspectos éticos, sociais e da cidadania.

\section{PROPOSTAS DE INSERÇÃO DA SOCIEDADE NA ESCOLA}

Justamente em função das grandes lacunas quanto à inserção da escola na sociedade, surgiu em Minas Gerais, a partir de propostas empresariais, em 1992, um projeto que insere as diretrizes da Qualidade Total na escola, com o apoio do próprio Secretário Estadual de Educação de Minas Gerais, também empresário. Este visava implementar nas escolas as concepções práticas sobre a Qualidade Total, desenvolvidas para as empresas no Ocidente e reestruturadas após a Segunda Guerra Mundial, principalmente no Japão. Barbosa, 1993 e Ishigawa,1991. O projeto foi elaborado pela Secretaria de Educação, com a assessoria da Fundação Christiano Ottoni. - Cunha,1995. A SEE/MG firmou para isso vários convênios com essa Fundação, a Secretaria Nacional de Ensino Tecnológico e o Banco Mundial.

Esse interesse surgiu no Brasil desde 1991, - segundo OLIVEIRA (1997),quando "assiste-se uma redefinição do empresariado na área educacional, tanto no que se refere a sua ação direta - formação de quadros intermediários -, quanto à indireta, aumentando as ações do Instituto Elvaldo Lodi - IEL, vinculado à Federação Nacional das Indústrias e do Instituto Herbert Levy - IHL, principalmente exigindo do Estado uma modificação da sua política educacional" [...] "O que foi detalhado no Plano do Ensino Fundamental e Competitividade Empresarial: uma proposta para o Governo, em 1991" [...] "Dois aspectos considerados críticos eram ali apontados pelos empresários: o financiamento e a qualidade do ensino. Em razão disso, houve interesse em criar em Minas Gerais um Projeto Piloto de Implementação da Qualidade Total - em 1992, bem como o Programa Municipal de Qualidade Total em Educação - 1994, que estabeleceram parcerias com empresas, objetivando a melhoria da infra-estrutura das instituições públicas." [...] "O Estado é responsável neles pela reciclagem 
dos docentes; a Fundação Christiano Ottoni, pelo treinamento no CQT e a empresa privada é convidada a entrar nessa parceria, possibilitando a construção da estrutura física necessária." Oliveira, op.cit.

Segundo OLIVEIRA (1997), ainda a análise dos resultados desse Plano Piloto, em sua pesquisa, "demonstrou que houve nos registros, uma drástica redução do fracasso escolar da escola pesquisada - Escola Estadual Madre Carmelita, situada numa região periférica na zona norte de Belo Horizonte - , após quatro anos de aplicação do CQT em dezessete escolas estaduais de Belo Horizonte - os índices de reprovação, que em 1991 eram de 45\%, em 1995 passaram a ser de apenas 6\%". A autora listou em seguida uma série de indicadores negativos, segundo os quais pela interpretação dos depoimentos de diferentes sujeitos vinculados à escola, esses excelentes índices obtidos resultaram: "da grande pressão exercida pela Secretaria de Educação, pela Fundação Christiano Ottoni, pela Diretoria da escola e pela professora de qualidade; do notório aligeiramento e fragilização dos conteúdos; da cooptação dos professores - promoção horizontal vinculada à aprovação discente, distribuição de prêmios, honrarias e solenidades para homenagear os docentes campeões de aprovação; do aumento da concorrência entre eles, da facilitação das exigências para a avaliação e do atrelamento das verbas escolares aos índices de promoção." - op.cit., Resumo.

Se formos relacionar essa avaliação acima com o diagnóstico que a SEE/MG fez quanto às "resistências oferecidas pelos professores e especialistas, pelos dirigentes educacionais e pela comunidade escolar, entre as possíveis razões do fracasso de muitas tentativas de renovação curricular em vários estados e países" , isso justificou também teria justificado a sua adoção de um "modelo aberto" de elaboração para sua atual e nova proposta curricular e dos "materiais correspondentes" em lugar dessa experiência de Qualidade Total na escola. Encontramos também nessas explicações uma justificativa possivel pela qual a atual gestão da SEE/MG tenha encerrado em 1995 o Projeto Piloto de Qualidade Total nessas escolas, bem como não dado continuidade aos convênios a ele vinculados.

Por outro lado, a avaliação da diretora de uma outra escola que participou também desse Projeto Piloto de Qualidade Total, foi de que "nas escolas onde,[assim como a dela, Escola Estadual Dona Augusta Gonçalves Nogueira, localizada ao lado de uma favela onde mora a maioria dos alunos], a Qualidade Total foi assumida como qualidade para a vida da escola e não como um tipo de qualidade introduzido para ser seguida como um trabalho extra, 
nessas escolas a melhoria da qualidade continuou, depois de encerrado aquele Projeto". Para ela, "o atual Programa de Qualidade é bom, mas o que ainda falta é por em prática mesmo a valorização do magistério , para dar melhores condições de capacitação e de vida aos professores, tanto quanto se está fazendo para a infra-estrutura de equipamentos da escola".

Apesar disso, para esta diretora - que se julga otimista - houve um grande crescimento também do interesse de participação dos pais no Conselho da escola; "até mesmo em discutir e aprender sobre quais as necessidades pedagógicas da escola"[...] "isso nos mostrou que durante esses anos já houve uma mudança muito importante na qualidade da escola para eles, assim como aumentou também o envolvimento dos seus filhos com ela, no início muito envolvidos na violência e depredação interna".

\section{ALGUMAS REPERCUSSÕES NOS PARADIGMAS EDUCACIONAIS DO ESTADO DE SÃO PAULO}

A Secretaria de Educação do Estado de São Paulo, após 1995, implementou um programa de mudanças educacionais, a partir da proposta de campanha da primeira gestão do atual Governador. Entre elas, estava principalmente a reorganização das escolas : "para acabar com a repetência; melhorar a qualidade do ensino e fazer com que todas crianças matriculadas na primeira série conseguissem chegar pelo menos até a oitava série". A partir do segundo semestre de 1995, depois de elaborado o Projeto da Reorganização da Rede de Escolas, " foram feitas reuniões com os diretores de escola, delegados de ensino, e entidades representantes de professores, pais e alunos visando a sua implementação. Isso foi reproduzido nas delegacias de ensino e nas escolas, com uma grande campanha de divulgação pelo rádio e pela TV. No mês de novembro, com as aulas suspensas, a população podia buscar esclarecimentos nas escolas diretamente com os professores." - O que já mudou na escola pública paulista?. (SEE-SP, 1997).

Esse processo de implementação das mudanças teve semelhanças notáveis, como podemos verificar no início do tópico anterior, com o debate amplo realizado também em Minas Gerais em novembro de 1995, sobre o "Documento Preliminar sobre as Políticas Públicas do Ensino Médio". Isso seguiu-se, de forma semelhante, ao que já fora antes estabelecido em sintonia com o Governo Federal sobre a Reestruturação da Educação Básica em Minas Gerais, como foi visto, quanto : 
" 1 - A implementação do Regime de Progressão Continuada do Ensino Fundamental, organizado em dois ciclos: $1^{\mathrm{a}}$ a $4^{\mathrm{a}}$ e $5^{\mathrm{a}}$ a $8^{\mathrm{a}}$ séries; 2 Condicionamento da conclusão ciclo ao resultado da avaliação realizada pelo Conselho de Classe, com base em avaliações efetuadas pelos professores ao longo do processo formativo do aluno durante o ano letivo; 3 - Criação de estudos complementares que deverão ser organizados entre o final do último ano letivo de cada ciclo e o início do seguinte - pelos alunos de desempenho considerado insatisfatório no final de cada ciclo; 4 - Oferta de currículos diferenciados pelas escolas, de acordo com suas possibilidades; 5 - Avaliação Contínua, com apresentação periódica dos resultados durante o ano letivo, pelo que o Conselho de Classe indicará a alternativa curricular mais adequada aos alunos no ano seguinte" (PROCAD/4 - SEE/MG/1998).

A Secretaria de Educação do Estado de São Paulo, no documento citado afirma, após dois anos de gestão, o sucesso da implementação do seu projeto de Reestruturação das Escolas: "se considerarmos que mais de $73 \%$ da Rede Escolar Estadual foi organizada e já funciona com um novo modelo pedagógico, temos que admitir que esta medida é um sucesso" [...] "Hoje temos cerca de 3000 escolas que já estão atendendo exclusivamente as crianças de $1^{\mathrm{a}}$ a $4^{\mathrm{a}}$ séries. Enquanto isso, outras 2000 passaram a receber apenas alunos mais velhos, da $5^{\mathrm{a}}$ série ao $2^{\circ}$ grau. Todas essas escolas receberam recursos para a compra de materiais pedagógicos, bem como para transformar as salas de aula em salas ambiente, ou seja, salas onde o ambiente estimula a aprendizagem"[...] "e o que é mais importante o número de escolas funcionando em quatro ou cinco turnos, onde os alunos mal entravam na classe e já estavam na hora de ir embora, diminuiu de 1039 para 537. Agora a maioria de nossas unidades - 6108 - têm no máximo três turnos: dois diurnos e um noturno". [...] "Todos os dias, mais de 2,5 milhões de alunos ficam uma hora a mais na escola"[...] "capacitar pessoal, escolher material didático, preparar o espaço físico, tudo isso pode ser feito melhor, porque a equipe escolar se concentra nos problemas e possibilidades de um grupo de alunos com características semelhantes. Equipes Técnicas foram reforçadas com a presença de 8000 coordenadores pedagógicos - professores aprovados em um processo de seleção e confirmados pelo Conselho de Escola"[...] "As classes de aceleração atendem cerca de 11000 alunos. Eles recebem aulas com professores preparados para lidar com crianças que passaram por várias repetências e usam livros e materiais adequados a sua idade e experiência. Com isso, em pouco tempo, eles podem recuperar o atraso e passar à série adequada a sua idade" op.cit. 
Esse conjunto de mudanças têm uma racionalidade instrumental, em relação à produtividade e qualidade do ensino. A elas se soma a descentralização e a municipalização do Ensino Fundamental, assumida como uma parceria voluntária entre os municípios e o Estado. Esta foi facilitada pela garantia dos recursos do Fundo de Valorização do Magistério e Desenvolvimento do Ensino Fundamental, criado pela Emenda Constitucional número 14, de iniciativa do Governo Federal e com base numa parcela da receita dos respectivos impostos. A proximidade do município com a escola e a comunidade são consideradas nessa política os principais fatores para um melhor atendimento e eficiência administrativa com a $\begin{array}{llll}\text { municipalização do Ensino } & \text { Fundamental. }\end{array}$

A autonomia e o poder de decisão das APMs, nesse contexto, também pode ser vista "em relação ao que elas podem e estão fazendo com as verbas recebidas ou enviadas diretamente às escolas"[...] "- compra de materiais e equipamentos didáticos para serem colocados nas salas de aulas - inclusive televisão com antena parabólica e vídeocassete; Contratação e execução de pequenas reformas e ampliações do prédio escolar, com supervisão de pessoal técnico através de convênios; - Contratação de serviços simples de manutenção da escola: conservação do jardim ou área externa, revisão das instalações hidráulicas e elétricas, pintura de algumas partes do prédio"[...] "Além disso, os pais estão participando também das decisões pedagógicas. Os Conselhos de Escola ajudaram na escolha do coordenador pedagógico da escola. Os professores que se interessaram em ocupar a função apresentaram um projeto pedagógico dirigido a sua escola e o Conselho escolheu o melhor. Também caberá ao Conselho confirmar no cargo os delegados de ensino".

Este conjunto de ações possíveis parecem estabelecer valores e atitudes dirigidas principalmente aos fins instrumentais da organização e da aprendizagem escolar. Dessa forma, o conceito de uma autonomia restrita às relações escolares parece estar distante de um processo de construção da cidadania e da identidade institucional da escola que esteja em ampla interação com a sociedade, conforme algumas interpretações feitas nesse sentido, a partir da LDB e dos pareceres da Câmara de Educação Básica do CNE, basearam também algumas das políticas analisadas nos tópicos anteriores deste trabalho. 


\section{ALGUNS ANTECEDENTES E DIRECIONAMENTOS FINAIS}

As influências existentes dos novos paradigmas educacionais nas escolas profissionais do Estado de São Paulo tiveram um impacto, também , na reorganização da Educação Básica Paulista, na medida em que, por exemplo, o presidente do Conselho Estadual de Educação foi significativamente, durante os últimos anos, um representante da direção do sistema SENAC, sob controle do setor empresarial.

Outra influência parece ter havido de tendências social-democratas atuantes, por exemplo, na política e no meio universitário paulista. Assim foram produzidas importantes propostas de mudanças políticas educacionais que se manifestaram em estudos realizados em órgãos da Universidade de São Paulo, tais como o Instituto de Estudos Avançados e outros.

Neste Instituto foi apresentado, por exemplo, um estudo no Seminário Políticas Públicas de Educação em 19/12/1991 cujas principais propostas do autor reapareceram, através do mesmo na qualidade de relator do Parecer da Câmara de Educação Básica do CNE, sobre as Diretrizes Curriculares Nacionais para o Ensino Médio, aprovado em 01/06/1996. Esse Parecer foi bastante comentado nos tópicos anteriores deste trabalho, tendo em vista a sua repercussão na educação básica, tanto no Estado de Minas Gerais como no Estado de São Paulo.

\section{REFERÊNCIAS}

ASSMANN, H. Pedagogia da qualidade em debate. Educação e Sociedade, Campinas, SP, v.14, n.46, p.476-502, dez. 1993.

CHESNEAUX, J. Modernidade-Mundo. Petrópolis : Vozes, 1995.

CORDANI, G. et al. A ciência aplicada e o progresso social. Estudos Avançados, São Paulo, v.8, n.20, p.7-50, 1994.

CONGRESSO NACIONAL DE EDUCAÇÃO, 2., 1997, Belo Horizonte. Anais... : Plano Nacional de Educação - Proposta da Sociedade Brasileira. Belo Horizonte : [s.n.], 1997. 
Tema: Educação na América Latina

DEMANGE, N. Transferência cultural : a educação num contexto de globalização. ProPosições, Campinas, SP, v. 5, n.15, p.19-23, 1994.

DIÁRIO OFICIAL. Lei n. 9.394 de 20-12-96. Diretrizes e bases da educação nacional. Brasília, DF : Imprensa Nacional, 1996.

FEDERAÇÃO DAS INDÚSTRIAS DE MINAS GERAIS. Prêmio FIEMG "Nansen Araújo" : parceria empresa - escola. Belo Horizonte : FIEMG, 1998.

GENTILLI, P. A, SILVA T.T. , (Org.). Neoliberalismo, qualidade total e educação : visões críticas. Petrópolis : Vozes, 1995.

GODOY, M.H., AMORIM, Rita de Cássia Sá. A mochila e o 5 S. Belo Horizonte : Ed. Fundação Christiano Ottoni, 1995.

GOODSON, I. Currículo: teoria e história. Petrópolis : Vozes, 1995.

GUBA, E.G. The paradigm dialog. Newsbury Park : Sage, 1990.

FLORES, V. Planificação estratégica. Caracas : CINTERPLAN, 1990.

HABERMAS, J. A crise de legitimação do capitalismo tardio. Rio de Janeiro : Tempo Brasileiro, 1980.

. El discurso filosófico de la modernidad. Madrid : Taurus, 1989.

- A nova intransparência : a crise do estado de bem-estar e o esgotamento das energias utópicas. Novos Estudos CEBRAP, São Paulo, n.18, 1987.

. Teoria de la acción comunicativa. Madrid : Taurus, 1987. 2v.

LATOUCHE, S. A ocidentalização do mundo. Petrópolis : Vozes, 1994.

BRASIL. Ministério da Educação e do Desporto. Secretaria do Ensino Fundamental.

Parâmetros Curriculares Nacionais. Brasília, DF : MEC, 1996.

BRASIL. Ministério da Educação e do Desporto. Conselho Nacional de Educação. Diretrizes curriculares nacionais para o ensino médio : parecer. Relatora Guiomar Namo de Mello. [Brasília, DF] : [s.n.], 1998.

BRASIL. Ministério da Educação e do Desporto. Secretaria de Educação Média e Tecnológica. PROMED : Programa de Melhoria e Expansão do Ensino Médio : diretrizes gerais. Brasília, DF : MED, 1999. (Mimeogr.).

(Mimeogr.)

. Educação Profissional - Legislação Básica. Brasília, DF : MED, 1998.

1998.

. PROEP : Programa de Expansão da Educação Profissional. [Brasília, DF] : [s.n.], 
Tema: Educação na América Latina

MELLO, G. N. Políticas públicas e educação. Estudos avançados, São Paulo, nv.5, n.13, p.747, 1991.

MINAS GERAIS (ESTADO). Secretaria de Estado da Educação. Ciclos de formação básica. Belo Horizonte : SEE/MG, 1997.

Acertando o passo : aceleração da aprendizagem para os alunos do II ciclo do ensino fundamental. Belo Horizonte : SEE/MG, 1998.

NOVOA, A. (Org.). As Organizações escolares em análise. Lisboa : Dom Quixote, 1992. OLIVEIRA, M. A. Qualidade, parceria e redenção : o projeto piloto de implantação da QT em uma escola estadual de Belo Horizonte. 1997. 220p. Tese (Doutorado). Faculdade de Educação, UNICAMP.

ORTIZ, R. Mundialização e cultura. São Paulo : Ed. Brasiliense, 1994.

PASSETTI, E. et al. Modernidade : globalização e exclusão. São Paulo : Imaginário, 1996.

PINTO, J. M. Administração e liberdade. Rio de Janeiro : Tempo Brasileiro, 1996.

POPKEWITZ, T. História do currículo, regulação social e pode. In : SILVA, T.T. da. O sujeito da educação. Petrópolis : Vozes, 1994.

PÓVOA FILHO, F.L. et al. Qualidade total na educação. Belo Horizonte : Fundação Christiano Ottoni, 1996. v.1.

SÃO PAULO (ESTADO). Secretaria de Educação. Programa de reforma do ensino público do Estado de São Paulo : a participação do conselho de escola na escola padrão. São Paulo, SP : SEE/SP, 1991.

O Que já mudou na escola pública paulista? São Paulo, SP : CECIP, 1997.

. Escola agora. São Paulo, SP : SEE/SP 1997.

. Escola agora. São Paulo, SP : SEE/SP 1998.

. Escola agora. São Paulo, SP : SEE/SP 1999.

ZABALDA, M. A. Planificação e desenvolvimento curricular na escola. Portugal : Edições ASA, 1994. 
